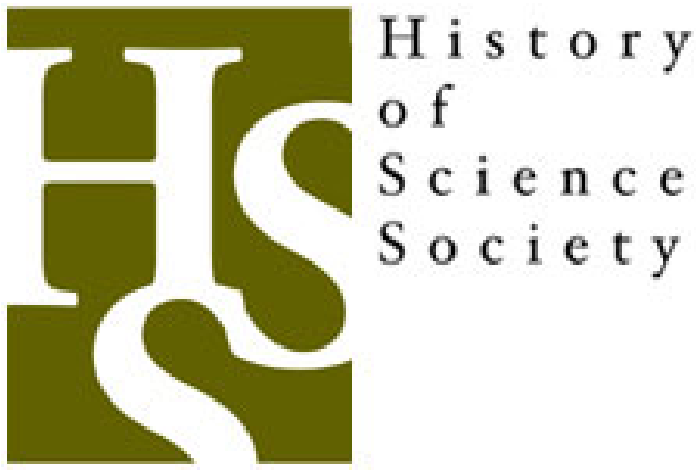

Sketching Together the Modern Histories of Science, Technology, and Medicine Author(s): John V. Pickstone

Source: Isis, Vol. 102, No. 1 (March 2011), pp. 123-133

Published by: The University of Chicago Press on behalf of The History of Science Society

Stable URL: http://www.jstor.org/stable/10.1086/657506

Accessed: 13/09/2011 11:18

Your use of the JSTOR archive indicates your acceptance of the Terms \& Conditions of Use, available at http://www.jstor.org/page/info/about/policies/terms.jsp

JSTOR is a not-for-profit service that helps scholars, researchers, and students discover, use, and build upon a wide range of content in a trusted digital archive. We use information technology and tools to increase productivity and facilitate new forms of scholarship. For more information about JSTOR, please contact support@jstor.org. 


\title{
Sketching Together the Modern Histories of Science, Technology, and Medicine
}

\author{
By John V. Pickstone*
}

\begin{abstract}
This essay explores ways to "write together" the awkwardly jointed histories of "science" and "medicine"- but it also includes other "arts" (in the old sense) and technologies. It draws especially on the historiography of medicine, but I try to use terms that are applicable across all of science, technology, and medicine (STM). I stress the variety of knowledges and practices in play at any time and the ways in which the ensembles change. I focus on the various relations of "science" and "medicine," as they were understood for a succession of periods-from mainly agricultural societies, through industrial societies, to our biomedical present - trying to sketch a history that encompasses daily practices and understandings as well as major conceptual and technical innovations. The model is meant to facilitate inquiry across topics and across times, including those to come.
\end{abstract}

T HIS ESSAY IS AN EXPERIMENT, using previous work to reach toward a schematic history of science, technology, and medicine, taken together as STM. It spans from the Renaissance to the present, with steps, as it were, around 1770, 1870, and 1970. Such periodizations, and their names, are always problematic, but here we move from mercantilist and aristocratic concerns with trade and land, to the age of revolutions (including the industrial), to the second industrial revolution and high modernism, and then to a present variously described as neoliberal, postindustrial, or postmodern. I refer to steps, rather than transitions, in order to stress the key aspect of this model: it is about the emergence of new features and the consequent reconfiguring of the old. I outline what I take to be the main configurations of STM before the late eighteenth century, in terms of natural philosophies, natural histories, and mathematics. I add elements that flourished around 1800 , notably the sciences of substantive analysis and technical rationalization. I go on to add the key novelties that came to dominate discussion, if not practice, in the century from roughly 1870 to roughly 1970 , notably the synthesis of new materials and systems; and,

\footnotetext{
* Centre for the History of Science, Technology, and Medicine (CHSTM), Simon Building, University of Manchester, Oxford Road, Manchester M13 9PL, United Kingdom; John.Pickstone@manchester.ac.uk.
} 
finally, I speculate about the additional new forms of our era. An explicitly cumulative, layered model may facilitate explanations of successive "steps" and help us explore the ways in which past forms are carried in the present, albeit modified and reunderstood.

I do not mean to imply that the present day is "better" because in some ways more complex, nor that important change comes only from the new features of an age- the recent advance of China, for example, owes much to the technologies and labor relations of the first industrial revolution. That I mostly discuss the West reflects my own limitations; perhaps the method will also prove useful for other geographies.

That such a model, even for the West, offers endless scope for disagreement is one of its virtues, but I hope the period characteristics given here fairly reflect some of the best recent work in the history of STM. I hope that readers will test it by imagining alternatives and by asking whether my method can be made to articulate usefully with the topics and cases they know best. I also hope that my ways of summarizing ways of knowing and working will allow for fertile exchanges between the histories of $\mathrm{S}, \mathrm{T}$, and $\mathrm{M}$ and with wider histories. ${ }^{1}$

\section{THE STM OF POSSESSIONS AND SPACES}

We can begin our tentative sketch for the period before circa 1800 by noting that while the term "medicine" is easily useful, the term "science" is not, at least in its modern sense ("technology" falls between). From the Renaissance through the eighteenth century, however, other terms for "genres" of knowledge/practice were relatively stable and remain helpful for historians. "Natural history," "natural philosophy," and "mixed mathematics" were common actors' categories, applicable across the whole field of STM; they can help us to distinguish the various objectives of practitioners, the "objects" of each genre, and their relations with the arts. ${ }^{2}$ To put it simply: natural philosophers dealt mainly in the meanings of the world; mathematicians in quantities; and naturalists in kinds, including minerals, plants, animals, and lots of other things and phenomena.

Much of the natural philosophy was exemplified in "physic," the senior of the medical arts; and because understandings of the human body were isomorphic and continuous with understandings of environments and of other human actions and products, that physic can help us see how the world at large was made up and its disorders managed. Most everyday problems, in agriculture or manufacture as well as in medicine, were easily correlated with particular remedies. Others, being more singular, were understood through "biographical" narratives that drew informally on natural histories and philosophies, mixing kinds and meanings. For more sophisticated diagnoses and prognoses, elite practitioners might use mathematics or draw more extensively on formal systems of natural philosophy-mostly humoral but with an increasing range of alternatives. These philosophies, like mathematics and natural history, were taught—and contested-largely through faculties of medicine. $^{3}$

Recent work on "sites of science" has detailed how mathematicians, naturalists, phi-

\footnotetext{
${ }^{1}$ This essay summarizes from and goes beyond John V. Pickstone, Ways of Knowing: A New History of Science, Technology, and Medicine (Manchester: Manchester Univ. Press, 2000; Chicago: Univ. Chicago Press, 2001); and Pickstone, "Working Knowledges Before and After circa 1800: Practices and Disciplines in the History of Science, Technology, and Medicine," Isis, 2007, 98:489-516. For obvious reasons, the references given here are very selective.

2 The importance of these categories is discussed in Pickstone, "Working Knowledges."

${ }^{3}$ See Harold J. Cook, "The History of Medicine and the Scientific Revolution," in this Focus section.
} 
losophers, and their patrons created systems for the cumulation and transmission of calculation and information, including observatories, instruments, maps, and places of communal demonstration; and museums, herbaria, gardens, anatomy theaters, chemical laboratories, (maybe) hospitals, and books that acted as collections. ${ }^{4}$ The ambitions of mathematicians to become philosophers, and of naturalists to promote historia as more than a preliminary to philosophy, were among the forces that helped multiply natural philosophies, partly through critique. ${ }^{5}$ As Hal Cook notes, contests around natural philosophy were crucial for medicine, and vice versa. The same was true for natural philosophy and theological disputations, including the need for cosmologies that would reconcile theological desiderata with the power of mathematics, with the desecration of the heavens brought about by discoveries such as Jupiter's moons, with the proliferation of animals and plants unknown to the ancients, and with the neo-Aristotelian characterization of the human heart as a muscular pump.

In histories written around World War II, it was the mathematization and mechanization of the world picture that received most attention. In our more biomedical world, scholarship has tended to focus on historia and on what we might call "naturalization"- the construction of natural objects, including diseases, by backgrounding the cultural aspects. Of course, naturalization was (and is) always partial, for-as Bruno Latour put it-we have never been modern; culture always accompanies nature, which is one reason for the current popularity of biographies of nonhumans. For the historical determinants of such "things," the best recent studies are on Golden Age Dutch culture and on its importation to Britain, on stately homes and coffee houses, on material culture, on patronage, on social networks, and on conspicuous consumption. In reconstructions of this world, physicians and naturalists (often the same people) have achieved a new centrality. The physician/ naturalist/entrepreneur Hans Sloane, who founded the British Museum collections and followed Newton as president of the Royal Society, tells us less than Newton about the heavens but quite a lot about the eighteenth century. ${ }^{6}$

In Enlightenment Europe, a concern with "improvement" helped create a new style of university, notably in Leiden, Göttingen, Edinburgh, and Montpellier, all of which were dominated by internationally attractive medical courses. ${ }^{7}$ Through these colleges, and through the growth of empires and imperial institutions, the eighteenth century saw major developments in mixed mathematics-feeding dreams of universal Newtonianism. In

\footnotetext{
${ }^{4}$ See the introduction and essays in Katharine Park and Lorraine Daston, eds., Early Modern Science (Cambridge History of Science, 3) (Cambridge: Cambridge Univ. Press, 2006).

${ }^{5}$ For stress on natural philosophy see, e.g., John Schuster, "The Scientific Revolution," in Companion to the History of Modern Science, ed. R. C. Olby, G. N. Cantor, J. R. R. Christie, and M. J. S. Hodge (London: Routledge, 1990), pp. 217-242; for mathematics see Peter Dear, Discipline and Experience: The Mathematical Way in the Scientific Revolution (Chicago: Univ. Chicago Press, 1995); and for natural history see Gianna Pomata and Nancy Siraisi, eds., Historia: Empiricism and Erudition in Early Modern Europe (Cambridge, Mass.: MIT Press, 2005).

${ }^{6}$ See, e.g., Harold J. Cook, Matters of Exchange: Commerce, Medicine, and Science in the Dutch Golden Age (New Haven, Conn.: Yale Univ. Press, 2007); Svetlana Alpers, The Art of Describing: Dutch Art in the Seventeenth Century (Chicago: Univ. Chicago Press, 1983); and Lisa Jardine, Going Dutch: How England Plundered Holland's Glory (London/New York: Harper Collins, 2008). Note the similar foci, on early modern ships and stuffs, in Thomas J. Misa's chapter on "Techniques of Commerce" in his admirable primer Leonardo to the Internet: Technology and Culture from the Renaissance to the Present (Baltimore: Johns Hopkins Univ. Press, 2004), Ch. 2.

${ }^{7}$ For an introduction and evidence that the French medical faculties covered most of "science" other than mixed mathematics see Laurence Brockliss, "Science, the Universities, and Other Public Spaces: Teaching Science in Europe and the Americas," in Eighteenth-Century Science, ed. Roy Porter (Cambridge History of Science, 4) (Cambridge: Cambridge Univ. Press, 2003), pp. 44-86.
} 
parallel, major extensions of natural history helped make classification, including the classification of diseases, a key intellectual preoccupation. But there were also new kinds of projects, working positivistically, not with preordained classical or Paracelsian principles, nor the mathematics of place and motion, but with new pragmatic and subjectspecific "elements" that could be systematically explored between natural philosophies and the crafts. One prime exemplar was Newton's dissection of light into colors; another was the medical chemistry of "mineral" solutions and affinities; and a third was the characterization of the parts of animals and humans. With them came the extension of systematic testing of technical processes, as in John Smeaton's work on water mills or Robert Bakewell's on animal breeding. All these projects proved seminal from the later eighteenth century, when political and economic structures came to "revolve" more rapidly. ${ }^{8}$

\section{THE AGE OF REVOLUTIONS: MEDICINE, INDUSTRY, AND THE CREATION OF NEW SCIENCES}

Historians of science may have downplayed their "scientific" revolution, of the seventeenth century, but historians of medicine still see the period from, say, 1780 to 1830 as the main chronological hinge in their subject; a view commonplace before Michel Foucault has remained so. Historians of technology, though now inclined with economic historians to more extended and nuanced accounts of "the industrial revolution," nonetheless remain faithful to industrialization as the major shift between the early modern and modern worlds. Historians of culture seem less inclined to explicit revolutions, but if you ask when philosophy took shape as a discipline- or seek to date the rise of aesthetics, the art market, or the institutionalization of research - most of the answers cluster in Germany around 1800. The connections with political revolutions are direct for France and important for Germany, especially through education; for Britain they weave through the emergence of industry and the new "great towns."

One might of course add the "second scientific revolution," though the current lack of attention to "big pictures" has left that notion as liminal as it is suggestive. ${ }^{10} \mathrm{We}$ undoubtedly have much of the historiographical material needed for a full synthesis, at least for the new sciences-led by work on chemistry, geology, medicine, and the institutions of STM in France, Germany, and Britain - but the integration remains tentative or partial, and more so for the wider and social history of STM. Though this essay is no place to attempt a summary of industrial history or urbanization, or the institutions and

\footnotetext{
${ }^{8}$ For exemplary recent works see Simon Schaffer, "Glass Works: Newton's Prisms and the Uses of Experiment," in The Uses of Experiment: Studies in the Natural Sciences, ed. David Gooding, Trevor Pinch, and Schaffer (Cambridge: Cambridge Univ. Press, 1989), pp. 67-104; Mi Gyung Kim, Affinity, That Elusive Dream: A Genealogy of the Chemical Revolution (Cambridge, Mass.: MIT Press, 2003); Ursula Klein and Wolfgang Lefèvre, Materials in Eighteenth-Century Science: A Historical Ontology (Cambridge, Mass.: MIT Press, 2007); and Hubert Steinke, Irritating Experiments: Haller's Concept and the European Controversy on Irritability and Sensibility, 1750-1790 (Amsterdam/New York: Rodopi, 2005).

${ }^{9}$ On the rise of aesthetics and the art market see, e.g., Terry Eagleton, The Ideology of the Aesthetic (Oxford: Blackwell, 1990); and Larry Shiner, The Invention of Art: A Cultural History (Chicago: Univ. Chicago Press, 2001). For a stimulating discussion of the politics of industrialization in Britain and France see Jeff Horn, The Path Not Taken: French Industrialization in the Age of Revolution, 1750-1830 (Cambridge, Mass.: MIT Press, 2006).

${ }^{10}$ The classic reference remains T. S. Kuhn, "Mathematical versus Experimental Traditions in the Development of Physical Science," in The Essential Tension: Selected Studies of Scientific Tradition and Change (Chicago: Univ. Chicago Press, 1977), pp. 33-65.
} 
practices of welfare and medicine, we can at least indicate how shifts in what came to be called "science" were configured and socially embedded. The historiography of medicine may be useful here, even though the medical arts came to seem ineffective compared to the triumphs of early nineteenth-century engineering.

My own understanding of the possibilities for historiographic integration derived from attempts to amend the common model of medical revolution and test its validity across the rest of STM. I wanted to preserve Foucault's sense of an epistemological break, while accepting that older modes of medicine continued in both old sites and new. I argued that "bedside" or biographical medicine remained characteristic of much of later medicine, especially of lay understandings and general practice. Indeed, such blends of natural history and meanings remain our common mode of understanding most of our material world, as ethnographies of recent technologies make clear. Yet we can still maintain that postrevolutionary France saw a new kind of medicine that focused on lesions in the tissues of corpses and that sought to understand patients in those (universal) terms. Foucault's Birth of the Clinic was attractive not just for dramatizing cognitive shifts but for showing how the creation of Paris medicine could be explained - through pre-existent "surgical views" and through shifts of power and contingencies that included reorganizations of welfare, professions, teaching, museums, and intellectual aspirations. ${ }^{11}$

Foucault had already shown how shifts in economics, philology, and biological sciences could be analyzed in ways that paralleled his account of medicine, albeit only at the level of ideas, and W. R. Albury had explored the contemporary shifts in general anatomy and physiology, revealing their relations to the new chemistry. ${ }^{12}$ It was not difficult to see the parallels, and in some cases interactions, with the range of new sciences at the Muséum d'Histoire Naturelle or the École Polytechnique, including the new sciences of work or heat, statistics, and the analysis of machines. In Germany, philosophy became a focused academic discipline and research became integral to university life, especially in philology, mathematics, and chemistry. The peculiar contributions of Britain included the analysis of power, factories, economic relations, and urban environments.

What then does this extension from the historiography of medicine chiefly suggest for a more integrated history of STM? Perhaps that chemistry was the main model of material analysis and of a (substantively) analytical science; it became the most prominent science in the nineteenth century and the prototype of a "scientific profession"-serving medicine, industry, and agriculture but becoming independent of them academically. More generally, that many new or remodeled sciences also understood their objects, and created their domains, in terms of specific elements (as well as natural history) — and that we might begin to understand these creations in terms of political and social change, as we undoubtedly can for Paris medicine.

At their foundations, both the École de Santé and the École Polytechnique emphasized practice rather than the autonomy of new disciplines. That practical emphasis, and the subservience of "preclinical sciences," remained characteristic of French medicine to the mid-twentieth century; and much the same was true of English medical schools, especially those based in hospitals rather than university colleges. But the Polytechnique soon

\footnotetext{
${ }^{11}$ Michel Foucault, The Birth of the Clinic: An Archaeology of Medical Perception, trans. A. M. Sheridan Smith (New York: Vintage, 1973).

${ }^{12}$ Michel Foucault, The Order of Things: An Archaeology of the Human Sciences (London: Tavistock, 1970); and W. R. Albury, "The Logic of Condillac and the Structure of French Chemical and Biological Theory, 1780-1801” (Ph.D. diss., Johns Hopkins Univ., 1972).
} 
became focused on mathematical sciences, partly as a selection mechanism, as also was the Cambridge Maths Tripos in England, where for much of the early nineteenth century conservatives maintained the superiority of mathematical sciences to experimental or applied sciences.

By contrast, the distinctiveness of the substantial analytical sciences came to be asserted through academic positions in German universities, and it was built into the specialist scientific societies that flourished in Britain. The individuality and mutual relations of the new sciences were outlined in Auguste Comte's influential histories and, in Britain, by William Whewell, for whom all these sciences had their own "ideas." Science in its modern sense was a collective created to order the many new sciences; but in that frame preclinical sciences and engineering analysis tended to be marginal, as they were also in the professional faculties. Historians of science tend to presume the proper autonomy of the modern scientific disciplines; studying medical faculties (and higher technical schools) could usefully acquaint us with alternative and more complex structures. ${ }^{13}$

Of course, to stress the new sciences is not to say that natural history and mixed mathematics ceased to be important or that natural philosophy ceased to be prominent in public discourse, albeit variously renamed. Medicine, for example, continued to have its philosophies; and much of medical practice was a blend of natural history and craft, as was much chemistry and engineering. The creations of the early industrial revolution involved crafts, knowledge of stuff and markets, a little mathematics, and the "practical analysis" that decomposed and mechanized craft activities. ${ }^{14}$ Would-be professionals used these resources and added new forms of commentary and organization; at this level, if not in terms of production, medical consultants could provide social models for chemists, including as agents of government.

The iconic creations of most nineteenth-century sciences were catalogues and atlases, not (just) of kinds but of compounds - chemical formulas, histological atlases, geological sections, morphological plans, charts of machine parts, and diagrams of prices and wages. Where old breeds of consultants had drawn on experience, new breeds might also see the compounds beneath the kinds, as it were, perhaps by using microscopes or measuring instruments. They tried to use their analytical sciences to reach below the merely empirical-and to establish a "clerisy" above the world of conflicting claims and material interests. ${ }^{15}$

In most kinds of engineering, elaborate analytical work was reserved for difficult cases, but the standardization of engineering production opened possibilities for synthesizing new machines. Chemistry could provide checks on ingredients, products, and waste, and some new processes could be scaled up. The effects of industry in towns were studied using chemistry, statistics, geology, political economy, and morbid pathology, to bolster the case for sanitation. In most of medicine, analysis was on the dead, because the dead (and animals) were more easily managed, compared, and dissected than were actual

\footnotetext{
${ }^{13}$ I tried to compare the national (and institutional) histories of "the sciences" in John V. Pickstone, "Science in Nineteenth-Century England: Plural Configurations and Singular Politics," in The Organisation of Knowledge in Victorian Britain, ed. Martin Daunton (Oxford: Oxford Univ. Press for the British Academy, 2005), pp. $29-60$.

${ }^{14}$ Ulrich Wegenroth, "Science, Technology, and Industry," in From Natural Philosophy to the Sciences: Writing the History of Nineteenth-Century Science, ed. David Cahan (Chicago: Univ. Chicago Press, 2003), pp. 221-253.

${ }^{15}$ See the discussions of mechanical objectivity in Lorraine Daston and Peter Galison, Objectivity (New York: Zone, 2007); and my essay review in British Journal for the History of Science, 2009, 42:595-600.
} 
patients. Though some doctors also drew on medical sciences to establish norms-and for therapy, as Michael Worboys emphasizes-the medical sciences that teachers advocated were mostly seen as laboratory alternatives to clinical medicine's empirical routines. Only around the end of the century would the "experimental medicine" of laboratories begin systematically to offer new modes of practice.

\section{THE SECOND INDUSTRIAL REVOLUTION, HIGH MODERNISM, AND SYNTHETIC NOVELTIES}

We have no Foucault for the later nineteenth century and the early twentieth century, but we have masses of good writing on modernism, including the stuff of the "second industrial revolution," which did encompass some biomedical productions. ${ }^{16}$ Dyestuffs then connected with synthetic pharmaceuticals, electrotechnics with medical applications of the new physics; vaccines and the new surgery were iconic technologies, and tropical medicine promised productive empires. By the mid-twentieth century, the apotheosis of physics and its technologies dominated visions of the future, but antibiotics offered to remake clinical medicine and the postwar migrations of physicists to biology and medicine helped create "biomedicine."

From about 1870, the development of new forms of scientific work was accompanied by the expansion and development of previous types, just as new industries ran alongside the expansion and refinement of the old. Museums and data banks grew, as they have since; and more kinds of analysis were developed, professionalized, and taught in the rapidly expanding universities and technical colleges. Chemical, histological, and then bacteriological analyses were allotted space in hospitals or associated institutions; advanced factories had sites for chemical and physical analysis of raw materials and products, though much analysis remained the preserve of independent "consultants." Laboratories, while far from new, were characteristic of many of the new social formations; and in this period many laboratories, like new hospitals and then schools, were specially designed for their functions. Indeed, the growth and institutionalization of analytical sciences and technologies, of scientific professions, higher education, large manufacturing corporations, materially sophisticated military establishments, and governmental bureaucracies, accounts for much of what historians of STM think of as modernist. It was the analytical aspect of that convergence of industry and the academy for which I have used the term "technoscience."17

But perhaps the key novelty in STM, and the main base for the growth of technoscience, was that analytical activities came to be complemented by forms of investigation and construction often described as synthetic or constructive. These depended not just on trial and error, or incremental improvements of prior constructions, or the use of synthesis to confirm analysis and so establish the constitutions of compounds, but on the development of analytical understandings to create specific constructs or control systems-some of which were imitations of the "natural," some of which were new. In some ways, synthetic

\footnotetext{
${ }^{16}$ See, e.g., Bernhard Rieger, Technology and the Culture of Modernity in Britain and Germany, 1890-1945 (Cambridge: Cambridge Univ. Press, 2005).

${ }^{17}$ See John V. Pickstone, "On Knowing, Acting, and the Location of Technoscience: A Response to Barry Barnes," Perspectives on Science, 2005, 13:267-278.
} 
chemistry was the model, as analytical chemistry had been previously, but engineering constructions were never far away. ${ }^{18}$

Experimental medicine proved most successful for vaccines and in correcting deficits or excesses in the endocrine system by injections of extracts or surgical removals of glands. Early experimental physiology had depended on animal vivisection, but experimental medicine also came to be associated with the extensions of human surgery made possible by anesthesia and by antisepsis. Inasmuch as human diseases could be modeled in animals, they could be analyzed experimentally and corrections could be engineered; here comparison with work on electrical engineering indicates how "pathological" analysis worked, both in labs and in the field. ${ }^{19}$

The development of laboratories as places of construction, as well as analysis, was prompted in electrotechnics when large-scale electrification required the creation and testing of many synergistic components. Synthetic chemistry provided many variants of dyestuffs and traditional remedies, from which effective compounds could be empirically selected. One can find similar shifts to "construction" in other fields related to engineering - for example, modernist architecture — and by the time of the Great War one sees a similar shift in avant-garde art, with the move from analytical to synthetic Cubism, or in Kandinsky's abstractions, and then more obviously in Constructivism and Futurism. By recognizing the relative novelty of synthesis in this period, and the dialectic with new forms of analysis, we may open more general ways of understanding modernism. ${ }^{20}$

From the standpoint of the twenty-first century, the post-World War II decades the French call "les trente glorieuses" appear as the high period of scientific modernism, with physics established as the fundamental science, electronics and nuclear sciences flourishing through state support and in large industrial companies, and a major growth of pharmaceuticals. The development of cell biology and genetics, together with the continued growth of biochemistry, linked "preclinical" medical sciences with botany, zoology, and biology—which had once been importantly "premedical." This complex of biomedical sciences was pursued in research institutes, universities, and hospitals, often in conjunction with the "clinical research" that had also received increased state support. The analytical methods were often derived from physical sciences, including those for the analysis of large biological molecules. But from the 1970s, recombinant methods helped transform "molecular biology" from a leading topic to a general method of biomedical analysis, while also opening possibilities of synthesis or genetic engineering. State support for science had never been greater; but seen now in retrospect, the ascendancy of Western industry, of welfare states, and of scientific professionals, academics, and doctors was under threat.

\footnotetext{
${ }^{18}$ In Ways of Knowing (cit. n. 1), I used "experimentalism" for what I would now call "synthetic experimentalism." I hope this revised terminology makes clearer that many experiments were and are analytical, rather than demonstrations of creation and control.

${ }^{19}$ Graeme Gooday, "Teaching Telegraphy and Electronics in the Physics Laboratory: William Ayrton and the Creation of an Academic Space for Electrical Engineering, 1873-84," History of Technology, 1991, 13:73-111.

${ }^{20}$ On the cultural centrality of synthetic "systems" especially in the early twentieth century see Peter Wagner, "Sociological Reflections: The Technology Question during the First Crisis of Modernity," in The Intellectual Appropriation of Technology: Discourses on Modernity, 1900-1939, ed. Mikael Hård and Andrew Jamison (Cambridge, Mass.: MIT Press, 1998), pp. 225-252.
} 


\section{NEOLIBERAL AND POSTMODERN STM? BLACK BOXES, INFORMATION, AND SIMULATIONS}

The landscape of sciences, technologies, and medicine has been transformed over the last forty years, and these recent developments are bound to refocus the histories thus lengthened. Biomedicine now ranks fully with the physical sciences in universities and research institutes, and it attracts more public attention. Medical industries are now a major part of the economy; and as technoscientific formations expand, the customary divisions between historians of science, medicine, and technology make less and less sense. As previously in physical sciences and technologies, the emblematic biomedical sites are now knowledge factories, with extensive division of labor. And all such fields and their publics are to some extent being reconfigured by the interactions of digitization, neoliberalism, and globalization. ${ }^{21}$

In "postindustrial" economies, as Paul Forman has noted, the modernist trope of "science and its applications" is being overlain by "technology and its knowledge infrastructure," and both the growth of intellectual property in science and the quantitative measurements of academic activity help commodify knowledge. ${ }^{22}$ These commodifications fit Western economies now dominated by automated production, by transactional professions, particularly "financial engineering," and by the hegemony of economics in many areas of governance.

The range of analytical methods deployed across STM has greatly increased; many of them are now mechanized, and the instruments have enormous throughputs. In biomedicine, both the inputs and the outputs of data can involve huge collections (living, dead, or in silico) and sophisticated management techniques that in some ways extend "natural history" along with many forms of comparative analysis. Machines can now multiply observations (e.g., using banks of living specimens and automatic photography) or they can multiply experiments - for analysis or for experimental syntheses. As noted earlier, synthesis is now part of biology as well as chemistry and engineering. If the present fashion for nanotechnology has specific meaning, it is that manipulations at the molecular level, across the whole of STM, can be envisaged as directly rearranging atoms.

Digitization also facilitates model building and simulation (which I see as mathematical synthesis). Simulations are central to fields such as meteorology, transport studies, and econometrics, as well as for models of living cells or galaxies. ${ }^{23}$ Students can now dissect virtual corpses, or analyze chemical specimens in silico, or play at designing therapeutic molecules. Several subtle ethnographers have explored these worlds, in which older teachers bemoan a loss of sensual reality while learners may feel that analysis on screen is more immediately real than the messing about with chemicals. ${ }^{24}$

The black-boxing of techniques, the massification of STM enabled by computers, the shared machines and data sources, and the dependence on technical specialists who can work across many different projects—plus the pursuit of commercial gain-all tend to

\footnotetext{
${ }^{21}$ I found particularly useful Robert Reich, The Next American Frontier (New York: Times Books, 1983). More specifically for STM see Dominique Pestre, Sciences, argent et politique: Un essai d'interprétation (Paris: Institut National de la Recherche Agronomique, 2003).

${ }^{22}$ Paul Forman, "(Re)cognizing Postmodernity: Helps for Historians-of Science Especially," Berichte Wissenschaftgeschichte, 2010, 33:1-19.

${ }^{23}$ For useful essays on computerized science see M. Norton Wise, ed., Growing Explanations: Historical Perspectives on Recent Science (Durham, N.C./London: Duke Univ. Press, 2004); and Sabine Leonelli, "Bio-ontologies as Tools for Integration in Biology," Biological Theory, 2008, 3:7-11.

${ }^{24}$ See Sherry Turkle, Simulation and Its Discontents (Cambridge, Mass.: MIT Press, 2009).
} 
further the "corporatization" of research organization and the technoscientific convergence of academic and industrial forms of organization. Forms of commercialization and research management once characteristic of industrial labs, and then of big physics projects, tend to spread across other academic fields, aided by hegemonic belief in the power of generic management. But there are also contrary reformations of industrial organization, including pharmaceuticals, where sets of operations previously managed in large companies are now contracted to specialist businesses that can develop products, run trials, or write professional articles. One major challenge across the historiography of STM is to share analyses of these shifts, including the commoditization of intermediate products, intellectual property, and the recent growth of "paper capitalism"-primarily concerned with transactions rather than substantive production and supporting the ascendancy of law, finance, accounting, and advertising (and maybe the codings and decodings of cultural studies).

Arguably the same shifts are reflected in the "protocols" of various technical fields, including the rise of neoempiricism in recent medicine. Medical schools are no longer dominated by the late nineteenth-century disciplines, the links between research, teaching, and practice are weakened, and lab training is no longer crucial for developing "scientific attitudes." The procedures of controlled experiments, often including randomization, developed first for experimental analysis of scientific variables, are now applied to assessments of the relative efficacy of medical procedures, especially drugs. The results, which were initially intended to inform judgments by professionals, are easily extended to become guidelines for managers and to judgments on the performance of professionals. Data on patient management and outcomes can also be fed into matrices, at once medical and economic, where diagnoses are plotted against treatments, outcomes, risks, and costs. In medicine, as in other technical fields, professionals can "mine data" and follow flow charts, at least officially.

The interplays between such statistical rationalizations and the mundane decisions by and about individuals are a challenge to historical inquiry across STM, as more generally are the relations of these new forms to older practices. Here again medical historiography may help-for doctors must judge at the level of the individual case, or through established measures of public health, and we now begin to see similarly normative approaches extended to planetary health or indices of well-being. This normative quality may be important for STM generally, as noted in the introduction to this Focus section, and so may the multiplicity of sites and encounters that medicine encompasses, not least through the activities of patients. Good histories can remind us, as Ilana Löwy suggests, that for all the proliferation of analytical methods and rationalizations, and of new constructions both mathematical and substantive, we mostly live in worlds of people and objects, of meanings and kinds, and it is there that we can assess the well-being of individuals, communities, and environments.

In closing, we can note that the relative decline of Western manufacturing industry, and the concomitant growth of wealth differentials, seems to have shifted Western public and scholarly attention from production to consumption-from factories to supermarkets, from public utilities to markets, and from social classes to networks. For these latter formations, eighteenth-century consumption often seems a better guide than the industrial society of the nineteenth or early twentieth century. As industry is hidden, in and from the West, so too fade the corresponding aspects of the historiography of STM, including the state-supported professions and the physical scientists devoted to disciplines and laws of nature. A wider geographical scope in the history of STM might usefully balance this 
tendency by focusing on the present sites of industry, the continued importance of old methods of production and transport, and the conditions of life and death on the margins of our supposedly global economy.

In the twenty-first century, our histories of STM need no longer begin with concepts rather than practices, physics rather than medicine- or the West/North rather than the East/South; but alternative analyses, including the historicization of the present, will require dynamic configurational models of topical breadth and chronological depth. Scientific revolutions will no longer suffice, even in the Kuhnian plural; still less the accumulation of illustrative microstudies, however thickly described or true to period.

This sketch now ended, with all its omissions, compressions, and simplifications, is meant to suggest ways of using the historiography of medicine toward wider historical readings of working knowledges — up to and beyond 2011. 